\title{
TRATAMENTO DA RETOCOLITE ULCERATIVA INESPECÍFICA EM CRIANÇA COM ENEMAS CONTENDO BUTIRATO. Relato de caso
}

\author{
Izaura Ramos ASSUMPÇÃO*, Maraci RODRIGUES** e Dorina BARBIERI***
}

RESUMO - Objetivo - Chamar a atenção para uma promissora alternativa terapêutica no tratamento de retocolite ulcerativa inespecifica em crianças. Método - É descrito o caso de uma criança com diagnóstico de retocolite ulcerativa inespecífica, com forma evolutiva crônica contínua, refratária a tratamento convencional e que foi tratada com enemas contendo butirato. Revisão de literatura pertinente ao caso foi realizada. Resultados - Paciente de 4 anos, feminina, parda, com diagnóstico de retocolite ulcerativa inespecifica desde 1 ano de idade e evolução refratária ao tratamento com corticóide (via oral e retal) e imunossupressor (6-mercaptopurina). Respondeu de modo satisfatório com melhora do quadro clínico, laboratorial, endoscópico e histológico, após o uso de enemas com butirato semelhante às descrições da literatura internacional. Conclusão - Embora sem estar esclarecido o mecanismo de ação do butirato na retocolite ulcerativa inespecifica, melhora significante foi observada neste caso, acenando como possibilidade terapêutica segura nos casos de retocolite ulcerativa inespecifica confinados a segmentos distais.

DESCRITORES - Colite ulcerativa. Butiratos. Criança.

Estudo realizado na Unidade da Gastroenterologia do Instituto da Criança do Hospital da Clínicas da Faculdade de Medicina da Universidade de São Paulo - ICr -HC-FMUSP.

* $\quad$ Médica Assistente da Unidade de Gastroenterologia do ICr HC FMUSP. Mestre em Medicina pela FMUSP.

** $\quad$ Médica Assistente da Unidade de Gastroenterologia do ICr HC FMUSP. Doutora em Medicina pela FMUSP

*** Ex-Chefe da Unidade da Gastroenterologia do ICr HC FM USP. Livre-Docente em Pediatria pela FMUSP.

Endereço para correspondência: Dra. Izaura Ramos Assumpção - Rua Capote Valente, 128 - apto.61 - Pinheiros - 05409-000 - São Paulo, SP. e mail: izaura@u-net.com.br 


\section{INTRODUÇÃO}

Ácidos graxos de cadeia curta (AGCC) são importantes para a manutenção da função e integridade da mucosa colônica. Os AGCC são formados no cólon através da fermentação bacteriana anaeróbica de carboidratos não digeridos e não absorvidos pelo intestino delgado. A maior fonte desses carboidratos presentes no cólon são as chamadas fibras dietéticas, que podem ser o amido resistente e a parede celular polissacarídica dos vegetais, também denominada de polissacárides nãoamido. Proteínas e aminoácidos também contribuem, em menor proporção, como fonte de AGCC ramificados. Os principais AGCC obtidos a partir da fermentação das fibras dietéticas são o acetato, o propionato e o butirato. Não há valor padrão de normalidade para a concentração molar dos AGCC no cólon e nas fezes, pois ele varia de acordo com o tipo e o estado físico da fibra dietética, o tipo e a quantidade de bactéria fermentadora e com o tempo de permanência dessas fibras no lúmen colônico ${ }^{(3,4,6)}$. SEGAL et al. ${ }^{(23)}$ demonstraram que africanos de raça negra tinham maior ingesta diária de fibras e, conseqüentemente, maior concentração de AGCC nas fezes, quando comparados com os africanos de raça branca.

De acordo com CUMMINGS et al. ${ }^{(4)}$, ceco e cólon direito são os sítios preferenciais de fermentação das fibras dietéticas, enquanto os segmentos colônicos mais distais são os responsáveis pela absorção dos AGCC. O mecanismo de absorção dos AGCC pelo colonócito ainda não está totalmente esclarecido, havendo sugestão de que ela ocorra através de troca iônica ${ }^{(26)}$.

O butirato é entre os AGCC o mais importante para a integridade do cólon, pois está intimamente relacionado com a proliferação, diferenciação e apoptose do colonócito, além da absorção de sódio, bicarbonato e água pelo cólon ${ }^{(5,10,12,17)}$. Além disso, a baixa freqüência de câncer e doença inflamatória do cólon na população negra africana em relação à população branca tem levado os autores a atribuírem a maior ingestão de fibras e maior concentração de AGCC nas fezes como fatores de proteção da mucosa colônica para essas doenças $^{(23)}$.

Alguns estudos foram realizados no sentido de se traçar o perfil dos AGCC nas fezes de pacientes com doença inflamatória do cólon, porém os resultados são controversos. ROEDIGER ${ }^{(16)}$ encontrou concentração elevada de AGCC nas fezes de pacientes adultos com RCUI e a relacionou com dificuldade do colonócito em oxidar o butirato, propondo, inclusive, que a RCUI fosse uma doença de deficiência energética celular, de possível causa intrínseca ao colonócito. Por outro lado, VERNIA et al. ${ }^{(28)}$ encontraram concentração diminuída de AGCC em pacientes com RCUI. HOVE e MORTENSEN $^{(9)}$ compararam a concentração de AGCC nas fezes de 230 pacientes com doença inflamatória do cólon, em diversas fases de atividade, com 70 pacientes controles com doença do trato gastrointestinal que não doença inflamatória e não observaram diferenças na concentração dos AGCC nas fezes nos dois grupos. TREEM et al. ${ }^{(26)}$ compararam a concentração de butirato nas fezes de crianças com doença de Crohn (DC) e retocolite ulcerativa inespecífica (RCUI) com controles normais e encontraram concentração aumentada nas fezes dos pacientes com leve e moderada atividade inflamatória, sugerindo inadequada utilização do substrato, mas diminuída naqueles com intensa atividade. Pacientes com atividade inflamatória mais intensa, normalmente apresentam mais sintomas como dor, distensão abdominal e diarréia, o que de certa forma restringiria a ingestão de fibras e outros substratos fermentativos, alterando a concentração dos AGCC.

Por outro lado, em 1990, FLORIN et al. ${ }^{(7)}$ observaram que pacientes com RCUI eram sistematicamente colonizados por bactérias redutoras de sulfato em relação aos controles, fato esse que fez ROEDIGER et al. ${ }^{(19)}$ sugerirem que o déficit energético do colonócito pudesse ser conseqüente à dificuldade de utilização do butirato pelo colonócito devido a fatores intraluminais como as bactérias redutoras de sulfato. De fato, o sulfito originado da redução do sulfato pelas bactérias impede a oxidação do butirato por diminuição da Coenzima-A. CHRISTL et al. ${ }^{(2)}$ demonstraram experimentalmente que sulfitos originados da redução de sulfato promovem lesões semelhantes às da RCUI.

Baseados nesses achados, BREUER et al. (1) utilizaram enemas contendo AGCC em indivíduos com RCUI e observaram melhora na atividade da doença, demonstrando que a mucosa inflamada se beneficiava com o contato de concentrações elevadas de AGCC. Como o substrato energético preferencial do colonócito é o butirato, estudos posteriores ${ }^{(20}$ $21,22,24,25)$ obtiveram bons resultados utilizando enemas contendo apenas o butirato.

A utilização de enemas retais, com volume de $100 \mathrm{~mL}^{(27)}$ permite distribuição adequada de drogas em cólon até ângulo esplênico, sendo, portanto, via de administração segura quando o sítio de interesse de ação da droga seja esse ${ }^{(13)}$. O objetivo do presente relato é apresentar a evolução de uma criança com RCUI refratária às terapias convencionais, que obteve melhora após o uso de enemas contendo butirato.

\section{DESCRIÇÃO DO CASO}

M.L.S., feminina, branca, procedente de São Paulo, SP, foi admitida na Unidade de Gastroenterologia do Instituto da Criança com 1 ano de idade e história de cinco a seis evacuações diarréicas diárias, com sangue vivo desde 7 meses de vida. Fez uso de leite materno exclusivo até os 5 meses, quando foi introduzido leite de vaca. Aos 10 meses de idade foi internada em outro serviço, 
recebendo alta após um mês com diagnóstico de alergia alimentar e prescrição de dieta hipoalergênica (mamadeira de frango), porém não apresentou melhora da sintomatologia até a época da admissão em nosso serviço. $\mathrm{O}$ peso encontrava-se no percentil 2,5 e a estatura no percentil 25. Ao exame físico apresentava-se emagrecida, descorada e sem outras características marcantes.

Os exames complementares mostravam: $\mathrm{Hb}-8,2 \mathrm{~g} / \mathrm{dL}$; Ht - 28,7 \%; leucócitos $8700 / \mathrm{mm}^{3}$; VHS - $30 \mathrm{~mm}\left(1^{\mathrm{a}} \mathrm{h}\right)$; albumina 3,3 g/dL; Alfa1 - 0,4 g/dL; Alfa2 - 0,9 g/dL; Beta - 0,9 g/dL; Gama - 0,3 g/dL; coproparasitológico e coprocultura - negativos. $\mathrm{O}$ estudo radiológico do trânsito intestinal resultou normal. A colonoscopia demonstrou reto, sigmóide e cólon descendente com perda de haustrações e do padrão vascular com mucosa esbranquiçada e espessada. O cólon transverso e o ceco mostravam inúmeras ulcerações rasas. O íleo terminal encontravase colonoscopicamente normal. A histologia mostrou íleo normal, cólons com colite crônica inespecífica com infiltrado eosinofílico e reto com alargamento de criptas, epitélio de caráter regenerativo, edema e discreto infiltrado linfoplasmocitário com raros eosinófilos na lâmina própria.

Os resultados permitiram a conclusão diagnóstica de RCUI, com pontuação igual a 82 pontos segundo LLOYD-STILL e GREEN $^{(14)}$. Tratamento específico foi introduzido, constituindo-se de manutenção da dieta hipoalergênica, prednisona ( $1 \mathrm{mg} / \mathrm{kg} / \mathrm{dia})$ e sulfasalazina (75 mg/kg/dia).

A paciente evoluiu com manutenção da diarréia e do sangramento, com queda dos parâmetros hematimétricos e da albumina sérica, apesar do aumento da dose de prednisona ( $2 \mathrm{mg} / \mathrm{kg} / \mathrm{dia}$ ) após quatro semanas do início do tratamento e várias séries de enemas com hidrocortisona. Após sete meses, devido à instabilidade clínica e laboratorial, foi associado 6-mercaptopurina ( $2 \mathrm{mg} / \mathrm{kg} / \mathrm{dia}$ ), que resultou em melhora do sangramento. Entretanto, durante os seis meses seguintes de evolução, as várias tentativas de redução da dose de prednisona resultaram em recurrência do sangramento.

Apesar das altas doses de corticóide tanto por via oral, como por enemas e imunossupressor, a criança apresentava recaídas clínicas freqüentes e manutenção da atividade inflamatória, colonoscópica e histologicamente. Seu peso mantinha-se entre os percentis 10 e 2,5 e a estatura abaixo do percentil 2,5. A idade óssea era de 1 ano e 6 meses para a idade cronológica de 3 anos e 4 meses.

Devido ao difícil controle da doença, principalmente em relação ao sangramento retal que originava inúmeras internações por anemia grave, um quadro de sepse e uma infecção por citomegalovírus optou-se pelo uso de enemas contendo butirato, aos 4 anos de idade. A paciente usou $100 \mathrm{~mL}$ de solução isotônica de butirato de sódio (SigmaAldrich $\left.{ }^{\circledR}\right)$, na concentração de $80 \mathrm{mmol} / \mathrm{L}$, por via retal, duas vezes ao dia: pela manhã antes de se levantar e à noite ao se deitar, sendo orientada a permanecer em posição de Trendelenburg por no mínimo uma hora.

No momento da introdução da terapia proposta, a pontuação segundo LLOYDSTILL e GREEN ${ }^{(14)}$ era 79 pontos e os exames complementares demonstravam: $\mathrm{Hb}$ 10,9 g/dL; Ht - 34\%; leucócitos - 9000/ $\mathrm{mm}^{3}$;


endoscopia digestiva alta era normal e a colonoscopia mostrava reto, sigmóide, cólon descendente, transverso e ascendente, com distensibilidade e haustrações normais. A mucosa de cólon descendente e sigmóide apresentava-se friável com erosões recobertas por fibrina e padrão vascular normal. O íleo terminal era colonoscopicamente normal. $\mathrm{O}$ estudo histológico demonstrou ileíte crônica inespecífica leve, ceco e cólon transverso com colite crônica inespecífica, sigmóide com colite crônica moderada inespecífica, com intensa atrofia de glândulas e reto com retite crônica inespecífica com intensa atividade inflamatória.

Após duas semanas de uso de enema com butirato, a criança apresentava-se sem diarréia e sem sangramento. $\mathrm{O}$ aspecto colonoscópico evidenciava desaparecimento da friabilidade da mucosa e das erosões de sigmóide. O padrão histológico revelou retite crônica de leve atividade inflamatória, com intenso componente eosinofílico.

A criança manteve-se assintomática por quatro semanas, após o término dos enemas, tendo sido possível a diminuição da dose de prednisona para $0,5 \mathrm{mg} / \mathrm{kg} /$ dia. Porém, voltou a apresentar diarréia e sangramento retal, sendo submetida a nova série de enemas, semelhante ao anterior, mas por período de seis semanas. Novamente houve regressão da sintomatologia, permanecendo assintomática até o momento (seis semanas após termino da segunda série de enemas), com melhora dos parâmetros laboratoriais, colonoscópico e histológico.

\section{DISCUSSÃO}

$\mathrm{O}$ aspecto evolutivo da RCUI na forma crônica contínua corresponde à freqüência de somente $12 \%$ na casuística da Unidade, contra 60 a $80 \%$ dos casos que evoluem na forma crônica intermitente ${ }^{(15)}$. Essa forma crônica contínua representa um desafio terapêutico, exigindo inúmeros e constantes ajustes de medicação, incluindo drogas de segunda linha.

O uso de 6-mercaptopurina (6-MCP) tem sido descrito em pacientes com doença inflamatória intestinal, constituindo-se em alternativa terapêutica nos casos de RCUI corticodependentes ${ }^{(11,15)}$. Entretanto, neste caso a resposta foi insatisfatória, pois todas as tentativas de diminuição da dose de prednisona, embora em uso de imunossu- 
pressor, resultaram em piora clínica, laboratorial, colonoscópica e histológica. Esse fracasso terapêutico levou as autoras a procurarem outras medidas, optando-se, então, pelo uso de enemas contendo butirato, baseado em estudos já $\operatorname{citados}^{(1,20,24)}$, que mostravam resposta satisfatória em grande parte dos pacientes assim tratados. A rápida e consistente melhora observada neste caso após o uso de enemas contendo butirato, permite vislumbrar nova medida terapêutica para RCUI, embora não se consiga ainda entender os mecanismos básicos envolvidos neste efeito.

A RCUI é uma doença inflamatória da mucosa e submucosa colônica, cujo mecanismo fisiopatológico básico não é conhecido. A hipótese de resposta imune alterada da mucosa colônica tem permitido o uso, com relativo sucesso, de drogas imunossupressoras e drogas inibidoras dos mediadores da resposta inflamatória. Por outro lado, a hipótese de doença de déficit energético do colonócito tem justificado o uso de substâncias como o butirato.

ROEDIGER $^{(18)}$ sugeriu que a deficiência de oxidação do butirato pela mitocôndria do colonócito na RCUI ocorra por diminuição da coenzima-A livre e SCHEPPACH et al. ${ }^{(20)}$ demonstraram que a Co-A está reduzida nestes pacientes.

Essa falência (porém não completa) da atividade metabólica com conseqüente déficit energético, seria a responsável pelas lesões e, segundo ROEDIGER ${ }^{(18)}$, poderiam ser revertidas através do efeito "em massa" quando se utiliza enemas de butirato, pois as concentrações elevadas utilizadas seriam capazes de desbloquear o déficit oxidativo.

Além da importância do butirato como combustível energético essencial ao colonócito, outras ações importantes desse ácido graxo, principalmente sobre a proliferação celular, têm sido descritas tanto para pa- cientes com câncer de cólon, como com RCUI, doença reconhecida como pré-neoplásica.

SCHEPPACH et al. ${ }^{(20)}$ utilizaram enemas contendo butirato, durante duas semanas, em 10 pacientes adultos com RCUI, com volume de $100 \mathrm{~mL}$ administrados em duas doses diárias, e obtiveram melhora clínica e da atividade inflamatória em todos e parada do sangramento retal em nove. Observaram que a zona de proliferação da cripta estava aumentada nos pacientes com RCUI, independentemente da fase de atividade da doença e sugeriram que essa hiperproliferação celular seja decorrente de maior "turnover" dos colonócitos necessário para reparação do dano ou da morte celular. Após o tratamento com butirato observaram significante redução dessa zona de proliferação, com parâmetros semelhantes aos controles. Aliás, o efeito do butirato sobre a proliferação celular já havia sido demonstrado em estudo anterior, in vitro, pelos mesmos autores utilizando células colônicas normais e células de linhagem cancerosa, revelando que o butirato tem efeito diferente para cada uma dessas células. Assim, enquanto o butirato estimula a proliferação celular na mucosa normal promove diferenciação nas células de linhagem de câncer de cólon.

FRANKEL et al. ${ }^{(8)}$ também já haviam observado experimentalmente em cultura de colonócitos de pacientes com RCUI, que a viabilidade celular estava diminuída e a proliferação celular aumentada em relação aos controles normais. A adição de butirato à cultura elevou a síntese protéica, sem aumentar a proliferação celular, sugerindo aumento do tamanho celular e melhora da função (diferenciação).

STEINHART et al. ${ }^{(24)}$ também trataram 10 pacientes adultos com RCUI, com enemas contendo $60 \mathrm{~mL}$ de solução de butirato em uma aplicação noturna e obtiveram desaparecimento dos sintomas em quatro pacientes, melhora em dois e ausência de resposta em quatro. Os autores sugerem que a diminuição do sangramento nos pacientes com RCUI ocorra por aumento da resistência vascular do cólon e melhora do fluxo sangüíneo. $\mathrm{O}$ menor volume dos enemas e a dose única noturna talvez tenham contribuído para resposta menos significativa que no tratamento utilizado por Scheppach.

Apesar dos achados não uniformes a respeito da resposta clínica ao tratamento e mesmo sobre o mecanismo de ação do butirato em pacientes com RCUI, é evidente a sua importância como combustível energético do colonócito e sua capacidade em desbloquear o processo oxidativo pelo efeito "em massa".

\section{CONCLUSÃO}

A etiopatogenia da RCUI, assim como o mecanismo de ação do butirato sobre a mucosa colônica doente, ainda não estão totalmente esclarecidos. Entretanto, o uso de enemas contendo butirato no presente estudo revelouse eficaz, pois houve parada do sangramento e melhora evidente no aspecto macroscópico e histológico de modo semelhante ao da literatura internacional. As autoras propõem que estudos utilizando enemas contendo butirato na RCUI sejam elaborados para a faixa etária pediátrica, pois se a sua eficácia permitir diminuição de doses de corticoesteróides ou mesmo sua retirada, assim como de drogas imunossupressoras, os efeitos colaterais indesejáveis decorrentes da terapêutica convencional serão minimizados. Os enemas contendo butirato se mostraram seguros e sem efeitos colaterais, uma vez que se utilizou substância normalmente produzida pelo próprio intestino. Entretanto, cabe lembrar que nem sempre a RCUI na criança está exclusivamente localizada em cólon descendente, sigmóide e reto, e mesmo quando se inicia nesses locais pode evoluir comprometendo cólon direito e ceco. Portanto, o uso de enemas com butirato na RCUI estaria condicionado às formas colônicas baixas. 
Assumpção IR, Rodrigues $M$, Barbieri D. Treatment of ulcerative colitis in child with enemas containing butyrate: case report. Arq Gastroenterol, São Paulo, 36(4):238-243, 1999.

ABSTRACT - Objective - To report a promising therapy to ulcerative colitis in children. Methods - We report a case of ulcerative colitis in 4 years old female, who had this diagnosis since she was 1 year old. The treatment of RCUI had an insatisfatory response to conventional therapys (retal and oral corticosteroids and immunosupressive agent). Results - She showed improvement, using enemas containing butyrate, in clinical, endoscopic and histological parameters. Conclusions - Although the role of butyrate in the treatment of ulcerative colitis still remains to be determined, we find effective response in this case. Despite evidences that butyrate may be benefical and safety in treating refractory distal ulcerative colitis, results of controlled trials, specially in children will be necessary to prove the efficacy of this therapy.

HEADINGS - Colitis, ulcerative. Butyrates. Child.

\section{REFERÊNCIAS BIBLIOGRÁFICAS}

1. $\quad$ Breuer RI, Buto S, Christ ML, Bean J, Vernia P, Paoluzi P, Di Paolo MC, Caprilli R. Retal irrigation with short-chain fatty acids for distal ulcerative colitis: Preliminary report. Dig Dis Sci, 36:185, 1991 .

2. Christl SU, Eisner HD, Dusel G, Kasper H, Scheppach W. Antagonistic effects of sulfide and buyrate on proliferation of colonic mucosa. Dig Dis Sci, 41:2477, 1996.

3. Cummings JH. Short chain fatty-acids in the human colon. Gut, 22:763, 1981

4. Cummings JH, Pomare EW, Branch WJ, Naylor CPE. Short chain fatty acids in human large intestine, portal, hepatic and venous blood. Gut, 28:1221, 1987.

5. Demigné C, Rénésy C. Stimulation of absorption of volatile fatty acids and minerals in the cecum of rats adapted to a very high fiber diet. J Nutr, 115:53, 1985.

6. Fleming SE, Arce DS. Volatile fatty acids: their production, absorption, utilization and roles in human health. Clin Gastroenterol, 15:787, 1986

7. Florin THJ, Gibson GR, Neale G, Cummings JH. A role for sulfate bacteria in ulcerative colitis. Gastroenterology, 98:A170, 1990. [Abstract].

8. Frankel W, Lew J, Su B, Bain A, Klurfeld D, Einhorn E, Mac Dermott RP, Rombeau J. Butyrate increases colonocyte protein synthesis in ulcerative colitis. J Surg Res, 57:210, 1994.
9. Hove H, Mortensen PB. Influence of intestinal inflammation and small and large bowel length on fecal short-chain fatty acids and lactate. Dig Dis Sci, 40:1372, 1995.

10. Jaskiewicz J, Zhao Y, Hawes J, Shimonura Y, Crabb DW, Harris R. Catabolism of isobutirate by colonocytes. Arch Bioch Bioph, 327:265, 1996 .

11. Korelitz BI, Wisch N. Long term therapy of ulcerative colitis with 6 Mercaptopurine: a personal series. Am J Dig Dis, 17:111, 1972.

12. Kripke AS, Fox AD, Berman JM, Settle RG, Rombeau JL. Stimulation of intestinal mucosal growth with intracolonic infusion of short-chain fatty acids. JPEN J Parent Enteral Nutr, 13:109, 1989.

13. Kruis W, Eisemberg J, Paumgartner G. Retrograde colonic spread of sulfasalazine enemas. Scand J Gastroenterol, 17:933, 1982.

14. Lloyd-Still JD, Green OC. Clinical scoring system for chronic inflammatory bowel disease in children. Dig Dis Sci, 23:620, 1979.

15. Rodrigues M, Barbieri D, Koda YKL, Faria RM. Retocolite ulcerativa inespecífica. In Barbieri D, Koda YKL, ed. Doenças gastroenterológicas em pediatria. Rio de Janeiro, Atheneu, 1996. p. 283.

16. Roediger WEW. The colonic epithelium in ulcerative colitis: an energy-deficiency disease. Lancet, 2:712, 1980.

17. Roediger WEW. Role of anaerobic bacteria in the metabolic welfare of the colonic mucosa in man. Gut, 21:793, 1980. 
18. Roediger WEW. The starved colon - diminished mucosal nutrition, diminished absorption and colitis. Dis Colon Rectum, 33:856, 1990.

19. RoedigerWEW, Duncan A, Kapanaris O, Millard S. Reducing sulfur compounds of the colon impair colonocyte nutrition: implications for ulcerative colitis. Gastroenterology, 104:802, 1993.

20. Scheppach W, Sommer H, Kirchner T, Paganelli GM, Bartran P, Christ S, Richter F, Dusl G, Kasper H. Effect of butyrate enemas on the colonic mucosa in distal ulcerative colitis. Gastroenterology, 103:51, 1992 .

21. Scheppach W. Treatment of distal ulcerative colitis with short chain fatty acid enemas. A placebo-controlled trial. Dig Dis Sci, 1:2254, 1996.

22. Scheppach W, Muller JG, Boxberger F, Dusel G, Richter F, Bartram HP, Christl SU, Dempfle CE, Kasper H. Histological changes in colonic mucosa following irrigation with short chain fatty acids. Eur J Gastroenterol Hepatol, 9:149, 1997.
23. Segal I, Hassan H, Walker ARP, Becker P, Braganza J. Fecal short chain fatty acids in South African urban Africans and whites. Dis Colon Rectum, 38:732, 1995.

24. Steinhart AH, Brzezinski A, Baker JP. Treatment of refractory ulcerative proctosigmoiditis with butyrate enemas. Am J Gastroenterol, 89:179, 1994.

25. Steinhart AH, Hiruki T, Brzezinski A, Baker JP. Treatment of left-sided ulcerative colitis whit butyrate enemas: a controlled trial. Aliment Pharmacol Ther, 10:729, 1996.

26. Treem WR, Ashan N, Shoup M, Hyans J. Fecal short chain fatty acids in children with inflamatory bowel disease. J Pediatr Gastroenterol Nutr, 18:159, 1994.

27. Van-Bodegraven AA, Boer RO, Lourens J, Tuynman HA, Sindram JW. Distribution of mesalazine in active and quiescent ulcerative colitis. Aliment Pharmacol Ther, 10:327, 1996.

28. Vernia P, Gnaedinger A, Hauck W, Breuer RI. Organic anions and diarrhea of inflammatory bowel disease. Dig Dis Sci, 33:1353, 1988. 